\title{
Degradation and Detoxification of Banana Postharvest Treatment Water Using Advanced Oxidation Techniques
}

\author{
Dunia E. Santiago, Elisenda Pulido Melián, Cristina Fernández Rodríguez, \\ José A. Ortega Méndez, Sebastián O. Pérez-Báez, José M. Doña-Rodríguez* \\ Grupo de Photocatálisis y Espectroscopía Aplicada al Medioambiente-FEAM \\ (Unidad Asociada al Instituto de Ciencia de Materiales de Sevilla, C.S.I.C.), CIDIA-Depto. de Química, \\ Edificio del Parque Científico Tecnológico, Universidad De Las Palmas De Gran Canaria, Las Palmas, Spain \\ E-mail: ${ }^{*}$ jdona@dqui.ulpgc.es \\ Received June 27, 2011; revised July 29, 2011; accepted August 4, 2011
}

\begin{abstract}
The elimination and detoxification of water contaminated with the principal commercial fungicides-thiabendazole (Textar $60 \mathrm{~T}$ ) and imazalil sulphate (Fruitgard IS 7.5) - used in the postharvest treatment of bananas was successfully achieved through the use of advanced oxidation processes (AOPs). The techniques tested were heterogeneous photocatalysis with $\mathrm{TiO}_{2}$ and $\mathrm{TiO}_{2}$-activated carbon $\left(\mathrm{TiO}_{2}-\mathrm{CA}\right)$ and Fenton and photo-Fenton processes. The evolution of fungicide concentration during degradation was studied together with mineralization and toxicity levels. When treated with any of the methods under study, the water meets the conditions stipulated by the legislation currently in force for its reuse in irrigation. However, this study proposes that the Fenton process is the best option for treatment of this type of water due to the efficiency of its reactions and its low economic cost.
\end{abstract}

Keywords: Thiabendazole, Imazalil Sulphate, Photocatalysis, Fenton, Photo-Fenton, Banana Postharvest

\section{Introduction}

The water under study represents a typical wastewater obtained after bananas have been washed as part of their postharvest treatment. In this postharvest treatment the fruit are normally washed two or three times in order to remove larger particles and any dust that might have been brought with the fruit from its growing area. A fungicide mixture is also applied to combat possible diseases, particularly crown rot, that might affect the fruit. Among the most commonly used fungicide mixtures are those studied in this work which are thiabendazole-based or imazalil sulphate-based [1].

This water contaminated with the postharvest fungicide is normally washed away into the sewage system. For a banana packing system of between 10 and 60 tons/ day, this represents a total daily volume of some $10000 \mathrm{~L}$ of water that needs to be washed away. The various wastewater samples analysed for this study contained concentrations of between 10 and $15 \mathrm{mg} \cdot \mathrm{L}^{-1}$ of imazalil sulphate or between 25 and $30 \mathrm{mg} \cdot \mathrm{L}^{-1}$ of thiabendazole. By law, this fungicide concentration must be removed before it is washed away into the sewer system. Legis- lation in the Canary Islands (Spain), one of the biggest banana producing regions, requires that concentrations of this type of substance must not exceed $0.05 \mathrm{mg} \cdot \mathrm{L}^{-1}$ [2]. However, because of the growing scarcity of the water resource in the Canary Islands as a result of overexploitation and contamination of the aquifers, the use of treated water for irrigation purposes is of particular interest. For this to be possible, restrictions related to quality indicators such as $\mathrm{BOD}_{5}, \mathrm{COD}$, nitrates, etc., must also be complied with in addition to the required fungicide threshold concentrations [3].

Studies have been published on the effectiveness of advanced oxidation techniques, specifically heterogeneous $\mathrm{TiO}_{2}$-based photocatalysis and the Fenton processes for the degradation of pesticides and fungicides in water [4-6]. These processes, although making use of different reacting systems, are all characterised by the same chemical feature: production of $\bullet \mathrm{OH}$ radicals [7].

In heterogeneous photocatalysis radiant energy is absorbed by the heterogeneous photocatalyst, a broadband semiconductor, in this case $\mathrm{TiO}_{2}$. The degradation reactions of the pollutants take place in the interfacial region without the catalyst undergoing chemical changes. 
To improve the efficiency of the $\mathrm{TiO}_{2}$, an inert surface like activated carbon is used as a support for the $\mathrm{TiO}_{2}$ to provide a large surface area. There are two main reasons for using adsorbents like this as support for the photoactive catalyst: firstly, to increase the size of the photoactive surface and secondly, to promote contact between the compound to be degraded and the catalyst by preconcentration of the pollutant at the semiconductor surface [8].

Studies have been undertaken which report that activated carbon increases not only the accessible surface area of the $\mathrm{TiO}_{2}$, as it impedes its aggregation, but also its decantability, acid-base properties and absorbance spectrum. This all leads to an improved photocatalytic performance. It has been established that the amount of activated carbon that maximises these benefits lies between $7 \%$ and $13 \%$ [9].

Fenton's reagent is an aqueous solution of hydrogen peroxide and ferrous ions which provides an important source of hydroxyl radicals and which, under acidic conditions ( $\mathrm{pH} 2-4)$, is a powerful oxidizing agent of organic compounds. Degradation rates increase substantially when the process is complemented with UV/visible radiation. In these cases it is known as a photo-Fenton process. The process becomes a photocatalytic one, as the $\mathrm{Fe}^{2+}$ oxidized to $\mathrm{Fe}^{3+}$ in the Fenton reaction is reduced again to $\mathrm{Fe}^{2+}$ by the action of radiation. Both reactions generate hydroxyl radicals [10].

The Fenton process has proven to be effective for the degradation of various compounds, including chlorinated aliphatic and aromatic compounds, nitroaromatics, azodyes, chlorobenzene, phenols, formaldehyde, herbicides, soil pollutants, etc. [11]. Fenton's reagent has also been successfully applied in the reduction of COD in municipal waste and ground waters and in leachate treatment. It is useful for the pre-treatment of non-biodegradable compounds [12]. Among the very few compounds that cannot be attacked by this reagent are acetone, acetic acid, oxalic acid, paraffins and organochlorine compounds [13].

The use of Fenton and photo-Fenton processes in the treatment of pesticide-containing wastewater has also been studied: the degradation of triazine herbicides [14], methyl-parathion [15], fenuron [16], the fungicides pyrimethanil and triadimenol [17], and commercial mixtures of pesticides [6, 18] are known examples.

The objective of this study is the removal of both thiabendazole and imazalil sulphate from the water used in the postharvest washing of bananas, using advanced oxidation techniques to comply with legislation governing wastewater disposal and/or water reuse for agricultural purposes. The effectiveness of four techniques is compared: heterogeneous photocatalysis based on $\mathrm{TiO}_{2}$ used alone and in combination with activated carbon, Fenton and photo-Fenton processes.

\section{Experimental}

\subsection{Characterisation of the water to be Treated}

Of the two fungicide mixtures under study in this work, one is thiabendazole-based $\left(\mathrm{C}_{10} \mathrm{H}_{7} \mathrm{~N}_{3} \mathrm{~S}\right)$ and the other imazalil sulphate-based $\left(\mathrm{C}_{14} \mathrm{H}_{16} \mathrm{Cl}_{2} \mathrm{~N}_{2} \mathrm{O}_{5} \mathrm{~S}\right)$, shown in Figure 1. The latter belongs to the imidazole chemical group and was developed to control postharvest diseases in fruit, particularly when there are problems of pathogen tolerance to benzimidazole fungicides like thiabendazole [19].

The fungicide mixtures were provided by the North Gran Canaria Agricultural Cooperative (Cooperativa Agrícola del Norte de Gran Canaria), which forms part of the Canary Island Banana Cooperative (COPLACA). The thiabendazole-based fungicide mixture was a $0.075 \%$ $(\mathrm{v} / \mathrm{v})$ solution of Textar $60 \mathrm{~T}$ which contained $60 \%(\mathrm{w} / \mathrm{v})$ of thiabendazole. The imazalil sulphate based fungicide mixture was a $0.6 \%(\mathrm{v} / \mathrm{v})$ solution of Fruitgard IS 7.5. The wastewater samples analysed in this study revealed concentrations of $25-30 \mathrm{mg} \cdot \mathrm{L}^{-1}$ of thiabendazole and 10 $15 \mathrm{mg} \cdot \mathrm{L}^{-1}$ of imazalil sulphate. Other chemical characteristics of both waste products are shown in Table 1.

\subsection{Materials and methods}

\subsubsection{Reagents/Chemicals}

The reagents used for the photocatalytic tests were: $\mathrm{TiO}_{2}$ (Degussa P25) and activated carbon supplied by Panreac (surface area: $778.28 \mathrm{~m}^{2} / \mathrm{g}$, pore volume: $0.454 \mathrm{~cm}^{3} / \mathrm{g}$, ash content: $<1 \%$, impurities: $\mathrm{Cl}^{-} \approx 0.2 \%$ ).

$35 \% \mathrm{H}_{2} \mathrm{O}_{2}$ (Scharlau) was used for the Fenton tests. Panreac dehydrated ferrous sulphate $(99 \%)$ was used as the $\mathrm{Fe}^{2+}$ source.

pH was adjusted with diluted $\mathrm{H}_{2} \mathrm{SO}_{4}$ and $\mathrm{NaOH}$.

Catalase was used to remove the $\mathrm{H}_{2} \mathrm{O}_{2}$ and avoid interferences with the analytical results (Micrococcus Lysodeikticus obtained from Fluka with $243075 \mathrm{U} \cdot \mathrm{mL}^{-1}$ ).

\subsubsection{Analytical Determinations}

Remaining concentrations of thiabendazole at different reaction times were HPLC-measured using a Supelco Discovery C18 $(25 \mathrm{~cm} \times 4.6 \mathrm{~mm}$ ID, $5 \mu \mathrm{m}$ particles $)$ and an acetonitrile-water-ammonia 40:60:0.6 solution as mobile phase, using a UV detector $(\lambda=280 \mathrm{~nm})$. Concentrations of imazalil sulphate were measured by the same method, using in this case an acetonitrile- $10 \mathrm{mM} \mathrm{KH}_{2} \mathrm{PO}_{4}$ solution (35:65) and $200 \mathrm{mg} \cdot \mathrm{L}^{-1}$ of sodium 1-octanedulfonate as mobile phase (adjusted to $\mathrm{pH} 3$ with phosphoric 
<smiles>c1ccc2[nH]c(-c3cscn3)nc2c1</smiles><smiles>C=CCOC(Cn1ccnc1)c1ccc(Cl)cc1Cl</smiles>

Figure 1. Thiabendazole molecule (left) and imazalil sulphate molecule (right).

Table 1. Parameters of interest of the water under study. Thiabendazole-based or imazalil-based fungicide mixtures.

\begin{tabular}{ccc}
\hline Parameters & Thiabendazole & Imazalil sulphate \\
\hline Concentration $\left(\mathrm{mg} \cdot \mathrm{L}^{-1}\right)$ & $25-30$ & $10-15$ \\
$\mathrm{pH}$ & 6.32 & 5.22 \\
$\mathrm{TOC}\left(\mathrm{mg} \cdot \mathrm{L}^{-1}\right)$ & $11-14$ & $11-12$ \\
Toxicity $(\% \mathrm{Inh})$. & $\approx 77 \%$ & $\approx 75 \%$ \\
BOD $\left(\mathrm{mg} \cdot \mathrm{L}^{-1}\right)$ & 20 & 20 \\
$\mathrm{COD}\left(\mathrm{mg} \cdot \mathrm{L}^{-1}\right)$ & 557.83 & 580.64 \\
$\mathrm{SS}\left(\mathrm{mg} \cdot \mathrm{L}^{-1}\right)$ & 128 & 120 \\
Nitrates $\left(\mathrm{mg} \cdot \mathrm{L}^{-1}\right)$ & 0.01 & 0.01 \\
Nitrites $\left(\mathrm{mg} \cdot \mathrm{L}^{-1}\right)$ & 0.00 & 0.00 \\
Sulphates $\left(\mathrm{mg} \cdot \mathrm{L}^{-1}\right)$ & 4.08 & 4.08 \\
Chlorides $\left(\mathrm{mg} \cdot \mathrm{L}^{-1}\right)$ & 2.52 & 2.52 \\
\hline
\end{tabular}

acid), with detection conducted at a wavelength of $\lambda=$ $225 \mathrm{~nm}$. The quantification of both fungicides was performed by least-squares fit [20].

Total organic carbon (TOC) was measured by using a TOC Shimadzu 5000-A.

The concentration of ions in solution was determined on a DIONEX Ionic Chromatograph equipped with a GP50 gradient pump, ED50 electrochemical detector and an IonPac AS11-HC column $(4 \times 250 \mathrm{~mm})$ using aqueous $\mathrm{NaOH}(30 \mathrm{mM})$ as eluent and a flowrate of 1 $\mathrm{mL} \cdot \mathrm{min}^{-1}$.

The toxicity of samples was determined by using the Lemna minor toxicity test [21]. Glass Petri dishes containing $13 \pm 2$ fronds of common duckweed (L. minor) were placed under constant visible radiation (one $18 \mathrm{~W}$ fluorescent tube placed approximately $25 \mathrm{~cm}$ above the test chambers) for $96 \pm 2 \mathrm{~h}$ in a chamber with an ambient temperature of $23 \pm 1^{\circ} \mathrm{C}$. Four replicates were used for each sample, which included a control without pollutant and samples taken at different reaction times. To $50 \mathrm{~mL}$ of solution, $0.5 \mathrm{~mL}$ of concentrated nutrient solutions were added. To each dish $15 \mathrm{~mL}$ of sample at $\mathrm{pH} 7.5$ - 8 were added. Growth inhibition percentage (I) was calculated with respect to the control without pollutant according to

$$
\mathrm{I}(\%)=(100 \mathrm{C}-\mathrm{T}) \mathrm{C}^{-1}
$$

where $\mathrm{C}$ and $\mathrm{T}$ are the frond number mean increments for the control and the sample, respectively.

$\mathrm{BOD}_{5}$ was analysed using special opaque and lightproof containers with an Aqualytic BOD-Sensor. COD was determined using the recovery technique with potassium dichromate $\left(\mathrm{K}_{2} \mathrm{Cr}_{2} \mathrm{O}_{7}\right)$ and SS using the filtration technique with $0.45 \mu \mathrm{m}$ filters [21].

\subsubsection{Experimental Conditions}

Prior to the degradation tests, both fungicide mixtures were filtered to remove suspended solids.

Degradation tests were conducted in $250 \mathrm{~mL}$ capacity Pyrex glass batch reactors.

For the heterogeneous photocatalytic degradation studies $200 \mathrm{~mL}$ volumes with $1 \mathrm{~g} \cdot \mathrm{L}^{-1}$ of Degussa P-25 $\mathrm{TiO}_{2}$ or Degussa P-25 $\mathrm{TiO}_{2}$ with $7 \%$ activated carbon were used. Aeration was maintained with an aquarium pump (EOLO AC3000 model: $2.5 \mathrm{~W}$ power, $2 \mathrm{~L} \cdot \mathrm{min}^{-1}$ output and pressure $>0.02 \mathrm{MPa}$ ) and a constant stirring rate of $450 \mathrm{rpm}$. A 60W Philips Solarium HB175 equipped with four $15 \mathrm{~W}$ Philips CLEO fluorescent tubes with emission spectrum from 300 to $400 \mathrm{~nm}$ (maximum around $365 \mathrm{~nm}$ ) was used as UV source in the degradation studies. The tests were conducted at natural $\mathrm{pH}$ and $\mathrm{pH} 5$, as various studies have reported that photocatalytic processes are more efficient at slightly acidic pHs [22].

For the Fenton and photo-Fenton tests various concentrations of $\mathrm{Fe}^{2+}$ and $\mathrm{H}_{2} \mathrm{O}_{2}$ were used, with reaction volumes of $200 \mathrm{~mL}$ and a working $\mathrm{pH}$ equal to 3 , adjusted with sulphuric acid. A constant stirring of 450 rpm was maintained. For the photo-Fenton reactions the Philips Solarium as described above was used as UV source. Catalase was used to remove excess $\mathrm{H}_{2} \mathrm{O}_{2}$ and to avoid interferences in the analytical and toxicity measurements.

After adsorption equilibrium was established, samples were taken to monitor the reaction in time intervals of 30 minutes or less, according to the kinetics established for each reaction. Before being measured the samples were filtered using $0.45 \mu \mathrm{m}$ syringe filters.

\section{Results}

\subsection{Thiabendazole}

\subsubsection{Photocatalysis: $\mathrm{TiO}_{2}$ and $\mathrm{TiO}_{2}+\mathrm{AC}$}

Figure 2 shows the results of thiabendazole degradation at natural $\mathrm{pH}(\mathrm{pH}=6.3)$ using the $\mathrm{TiO}_{2}$ based photocatalytic process. It can be seen that after 120 minutes of reaction time $95 \%$ of the thiabendazole present in the sample has been removed and after 390 minutes the amount of thiabendazole falls below the wastewater limit $\left(0.05 \mathrm{mg} \cdot \mathrm{L}^{-1}\right)$ as laid down in Canary Island (Spain) legislation. 


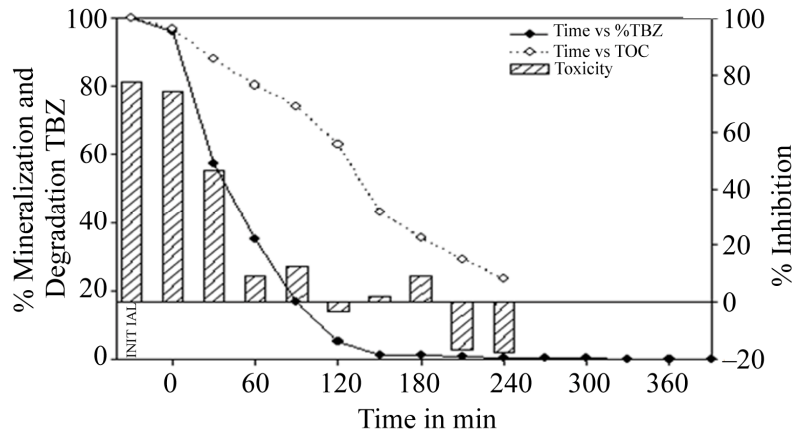

Figure 2. Thiabendazole concentration, TOC and toxicity evolution during the photocatalytic treatment of a $25 \mathrm{mg} \cdot \mathrm{L}^{-1}$ thiabendazole aqueous solution at natural $\mathrm{pH}(6.3)$ using 1 $\mathrm{g} \cdot \mathrm{L}^{-1}$ of $\mathrm{TiO}_{2}$.

TOC kinetics are much lower than for degradation. So, after 120 minutes only $37 \%$ of the compound had been mineralized, rising to $76 \%$ after 240 minutes.

As can be observed, the initial sample had a toxicity value equivalent to an inhibition level of $77 \%$. This falls to non-toxic values after 120 minutes of reaction time and, though small toxicity values can be detected in the following minutes, the sample becomes completely nontoxic after 210 minutes. Negative values are now given as a result of the nutritive character the sample acquires with the growth of Lemna minor.

Figure 3 shows the results for photocatalysis with 7\% $\mathrm{AC}-\mathrm{TiO}_{2}$. Figure 3(a) shows the results for photocatalysis with $7 \% \mathrm{AC}^{-} \mathrm{TiO}_{2}$ and illumination from commencement of the test. It can be seen that the thiabendazole degrades rapidly up to 90 minutes of reaction time, when $61 \%$ of the initial concentration has been removed. However, it is not until 240 minutes that the amount of this fungicide has fallen below the limit of $0.05 \mathrm{mg} \cdot \mathrm{L}^{-1}$. The mineralization rate falls more progressively, with a remaining TOC of $39.2 \%$ after 90 minutes and $18.1 \%$ after 240 minutes.

A fall in toxicity is observed from initial inhibition levels of $77 \%$ to $6 \%$ at 90 minutes. Toxicity ceases after 120 minutes.

Figure 3(b) underlines the adsorbent effect of activated carbon, as the reactor is left in darkness for the first hour before illumination commences. During the first 30 minutes a rapid decrease can be observed of up to $33 \%$ of the initial concentration. Thirty minutes after illumination commences $97.8 \%$ of the initial thiabendazole has been degraded, though it is not until 180 minutes of illumination that the concentration falls below the limit of $0.05 \mathrm{mg} \cdot \mathrm{L}^{-1}$. The same values are obtained after one hour of illumination as when illumination is used from the beginning of the reaction. This shows that the period of darkness has had no other effect than to delay the mineralization and detoxification processes. The toxicity

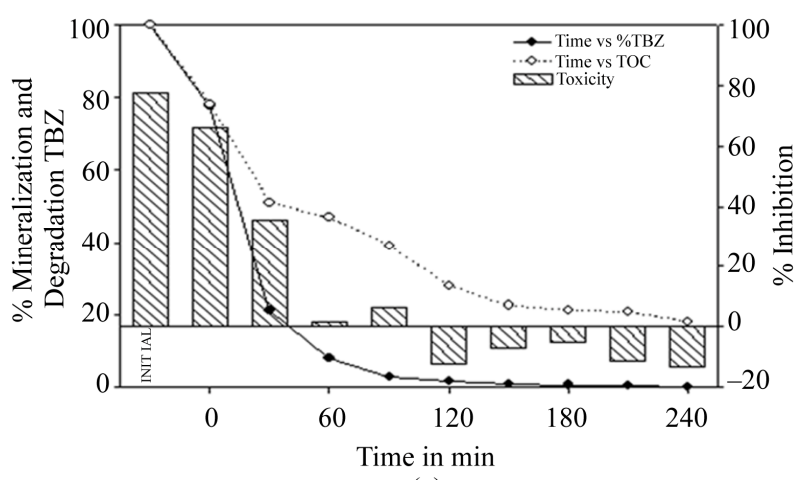

(a)

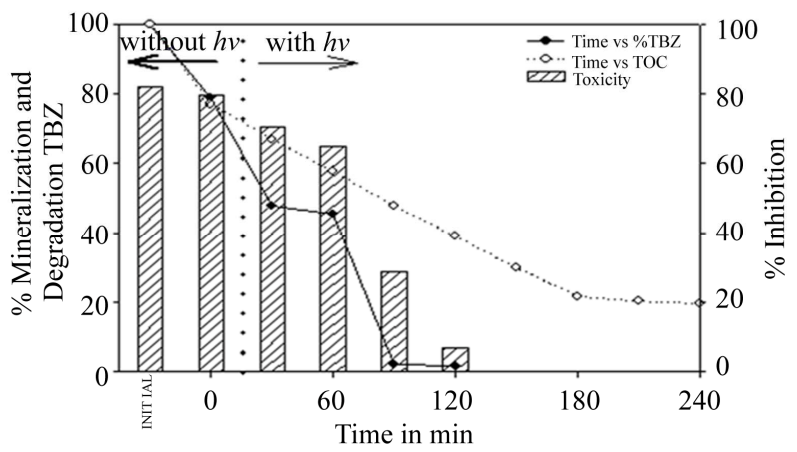

(b)

Figure 3. (a) Thiabendazole concentration, TOC and toxicity evolution during the photocatalytic treatment of a 25 $\mathrm{mg} \cdot \mathrm{L}^{-1}$ thiabendazole aqueous solution using $1 \mathrm{~g} \cdot \mathrm{L}^{-1}$ of $7 \%$ $\mathrm{AC} / \mathrm{TiO}_{2}$ composite as catalyst. (b) Thiabendazole concentration, TOC and toxicity evolution during the photocatalytic treatment of a $25 \mathrm{mg} \cdot \mathrm{L}^{-1}$ thiabendazole aqueous solution using $1 \mathrm{~g} \cdot \mathrm{L}^{-1}$ of $7 \% \mathrm{AC} / \mathrm{TiO}_{2}$ composite as catalyst but leaving the system without light for 1 hour.

level falls only slightly in the period of darkness, reaching an inhibition level of $65 \%$ at the end of that period.

\subsubsection{Fenton and photo-Fenton}

Firstly, the optimal concentration of reagents $\left(\mathrm{Fe}^{2+} / \mathrm{H}_{2} \mathrm{O}_{2}\right)$ was determined for fungicide treatment by Fenton and photo-Fenton processes, namely $6.03 \mathrm{mg} \cdot \mathrm{L}^{-1} / 1.25 \mathrm{ml} \cdot \mathrm{L}^{-1}$ and $5 \mathrm{mg} \cdot \mathrm{L}^{-1} / 0.25 \mathrm{ml} \cdot \mathrm{L}^{-1}$, respectively. With these concentrations, kinetic studies of thiabendazole degradation, mineralization and detoxification were then undertaken.

Figure 4(a) shows how the concentration of thiabendazole falls very quickly in the first 60 minutes of the Fenton reaction, with $98.9 \%$ of the fungicide removed and $27 \%$ mineralization. However, it is not until 240 minutes have elapsed that a value below the limit of 0.05 $\mathrm{mg} \cdot \mathrm{L}^{-1}$ is achieved, corresponding to $54.5 \%$ mineralization. Toxicity levels also respond favourably, with total detoxification occurring after 60 minutes of reaction time.

The results obtained using the photo-Fenton process (Figure 4(b)) show high degradation of the compound at 
30 minutes (up to $99.7 \%$ ). As of this point, the sample is no longer toxic. However, it is not until 90 minutes have elapsed that a concentration value below the limit of 0.05 $\mathrm{mg} \cdot \mathrm{L}^{-1}$ is achieved. At this point there is a corresponding $47 \%$ TOC removal. Though both the Fenton and photo-Fenton processes manage to lower thiabendazole content to values of $0.05 \mathrm{mg} \cdot \mathrm{L}^{-1}$, the photoFenton process additionally achieves a better mineralization rate of up to $80 \%$ in 250 minutes. Even so, both processes require less time for the fungicide treatment than the $\mathrm{TiO}_{2}$ process.

\subsection{Imazalil Sulphate}

\subsubsection{Photocatalysis: $\mathrm{TiO}_{2}$ and $\mathrm{TiO}_{2}+\mathrm{AC}$}

Figure 5(a) shows the results of photocatalytic degradation with $\mathrm{TiO}_{2}$ at the original $\mathrm{pH}$ of the sample,containing $15 \mathrm{mg} \cdot \mathrm{L}^{-1}$ of imazalil sulphate. Very rapid degradation can be observed during the first 30 minutes, reaching a degradation level of $98.2 \%$. A fungicide concentration level of $0.05 \mathrm{mg} \cdot \mathrm{L}^{-1}$ was achieved after 60 minutes of reaction time.

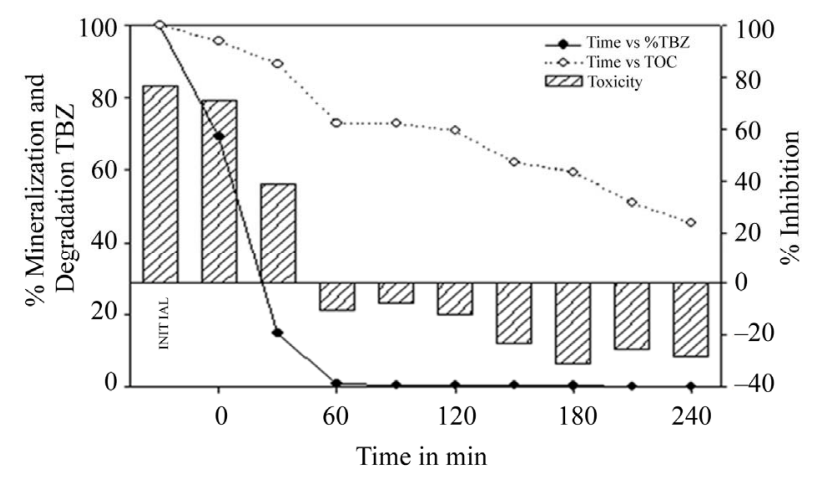

(a)

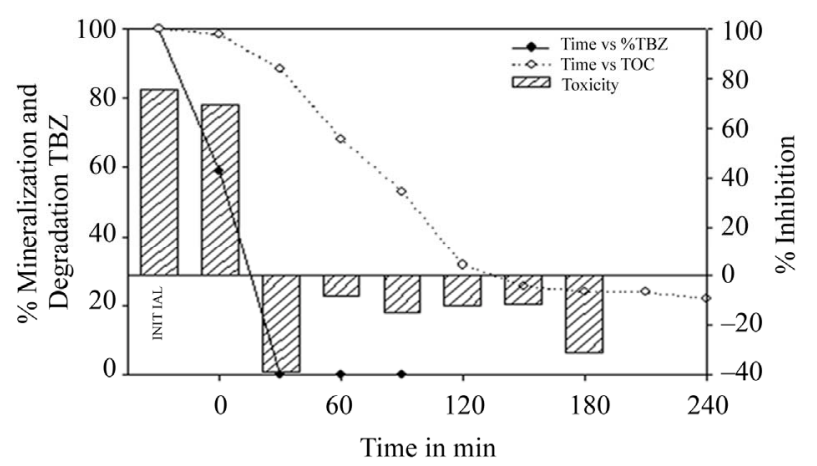

(b)

Figure 4. (a) Thiabendazole concentration, TOC and toxicity evolution during the Fenton treatment of a $25 \mathrm{mg} \cdot \mathrm{L}^{-1}$ thiabendazole aqueous solution using $6.03 \mathrm{mg} \cdot \mathrm{L}^{-1}$ of $\mathrm{Fe}^{2+}$ and $1.25 \mathrm{ml} \cdot \mathrm{L}^{-1}$ of $\mathrm{H}_{2} \mathrm{O}_{2}$. (b) Thiabendazole concentration, TOC and toxicity evolution during the photo-Fenton treatment of a $25 \mathrm{mg} \cdot \mathrm{L}^{-1}$ thiabendazole aqueous solution using 5 $\mathrm{mg} \cdot \mathrm{L}^{-1}$ of $\mathrm{Fe}^{2+}$ and $0.25 \mathrm{ml} \cdot \mathrm{L}^{-1}$ of $\mathrm{H}_{2} \mathrm{O}_{2}$.
Toxicity levels show a significant decrease as the concentration of imazalil sulphate falls, ceasing to be toxic after 30 minutes despite a still high TOC content of $74 \%$. Slight mineralization is observed until 60 minutes of reaction time, at which point there begins a sharp fall. This might be due to the presence of difficult-to-remove intermediates in the first stages of degradation.

Figure 5(b) shows the results when $\mathrm{TiO}_{2}-7 \% \mathrm{AC}$ is used as catalyst. A very rapid fall of the fungicide concentration is observed in the first 20 minutes (94.7\%), a fall which continues progressively until its total elimination after 60 minutes of reaction time.

Mineralization decreases at a slower rate. After 30 minutes of reaction time $56.6 \%$ of the initial TOC has been removed. However, as in the case of $\mathrm{TiO}_{2}$ the sample ceases to be toxic after 30 minutes reaction time.

\subsubsection{Fenton}

Optimization of the concentrations of the reagents $\mathrm{H}_{2} \mathrm{O}_{2}$ and $\mathrm{Fe}^{2+}$ for the Fenton process in the degradation of imazalil sulphate gave values of $0.05 \mathrm{~mL} \cdot \mathrm{L}^{-1}$ and 6.03 $\mathrm{mg} \cdot \mathrm{L}^{-1}$ respectively.

Figure 6 shows the results of degradation, mineralization and detoxification when applying the Fenton process to a $15 \mathrm{mg} \cdot \mathrm{L}^{-1}$ concentration of imazalil sulphate.

It can be seen how the imazalil sulphate concentration falls rapidly, with only $2.6 \%$ of the initial concentration remaining after just one minute of the process, though the fall in mineralization has only been $17.4 \%$. It is not until 30 minutes have elapsed that an imazalil sulphate concentration below $0.05 \mathrm{ppm}$ is reached. The TOC decreases slightly until the 20 minute point, with $80.7 \%$ of the initial amount remaining in solution. As of this point the decrease is much slower, with only $23.5 \%$ removed after 90 minutes of the process. Despite this persistence of degradation of the intermediates, toxicity levels tend to fall as the reaction progresses, from an initial inhibition value of $76 \%$ to $17 \%$.

The photo-Fenton process was not applied in the study of this fungicide due to the good results obtained from the Fenton reaction on its own.

\section{Discussion}

It can be clearly seen for thiabendazole degradation that the photo-Fenton process provided the most efficient reaction, followed by the Fenton reaction, the combination of titanium dioxide and activated carbon, and finally the least efficient reaction using only titanium dioxide as catalyst. Though all processes led to a concentration of the compound below $0.05 \mathrm{mg} \cdot \mathrm{L}^{-1}$, the photoFenton method was the fastest to achieve this figure. In general, inhibition of the thiabendazole degradation was 


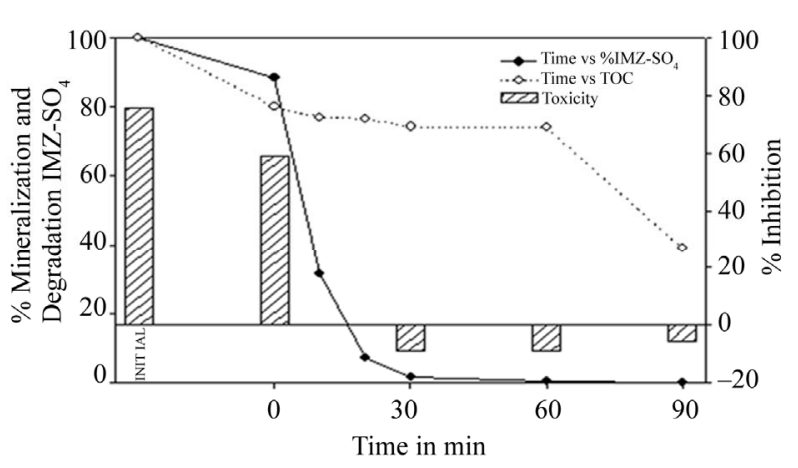

(a)

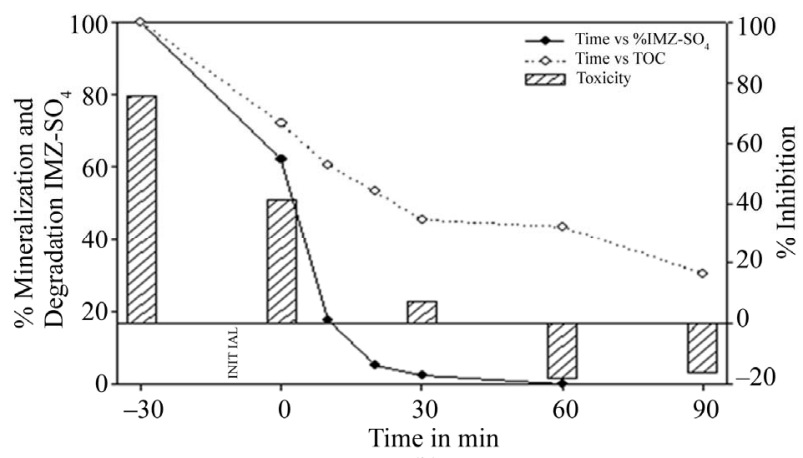

(b)

Figure 5. (a) Imazalil sulphate concentration, TOC and toxicity evolution during the photocatalytic treatment of a $15 \mathrm{mg} \cdot \mathrm{L}^{-1}$ Imazalil sulphate aqueous solution at natural $\mathbf{p H}$ (5.22) using $1 \mathrm{~g} \cdot \mathrm{L}^{-1}$ of $\mathrm{TiO}_{2}$. (b) Imazalil sulphate concentration, TOC and toxicity evolution during the photocatalytic treatment of a $15 \mathrm{mg} \cdot \mathrm{L}^{-1}$ Imazalil sulphate aqueous solution at natural $\mathrm{pH}(5.22)$ using $1 \mathrm{~g} \cdot \mathrm{L}^{-1}$ of $7 \% \mathrm{AC} / \mathrm{TiO}_{2}$ composite as catalyst.

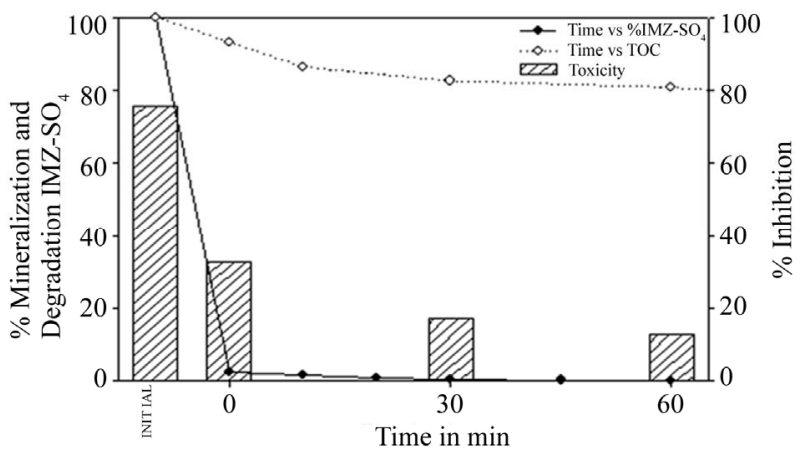

Figure 6. Imazalil sulphate concentration, TOC and toxicity evolution during the Fenton treatment of a $15 \mathrm{mg} \cdot \mathrm{L}^{-1}$ Imazalil sulphate aqueous solution using $5 \mathrm{mg} \cdot \mathrm{L}^{-1}$ of $\mathrm{Fe}^{2+}$ and $0.25 \mathrm{ml} \cdot \mathrm{L}^{-1}$ of $\mathrm{H}_{2} \mathrm{O}_{2}$.

observed at low concentrations. So, in the $\mathrm{TiO}_{2}$ based photocatalytic process only $5 \%$ of the compound is degraded between 120 and 390 minutes of illumination. This figure improves in the presence of activated carbon, which has a positive effect on the photocatalytic process as it enables pollutants to get closer to the photoactive surface of the $\mathrm{TiO}_{2}$.

The mineralization kinetic displays slower evolution than the fungicide degradation due to the intermediates generated in the course of the reaction. Evolution of the TOC shows greater efficiency in the titanium dioxide and activated carbon based process, with the least efficient process being the Fenton process.

The analysis of toxicity is of great importance as, during the degradation processes, intermediates are produced which could turn out to be more toxic than the original contaminant itself [23]. Favourable evolution of toxicity was noted for all the tested processes and for both fungicides. However, the first hour of the reaction was the most efficient, with a much faster degradation kinetic, especially in the photo-Fenton process. For this parameter, the least effective process was photocatalysis with $\mathrm{TiO}_{2}$, which can be improved by adding activated carbon to the process as a support to the catalyst. After 120 minutes reaction time the samples cease to be toxic in all the cases despite the remaining organic carbon content.

Very high efficiency levels with short reaction times were obtained for imazalil sulphate in all the tested processes. The time periods are lower than those obtained for thiabendazole due to the fact that there was a lower initial concentration of imazalil sulphate. In the heterogeneous photocatalysis process with $\mathrm{TiO}_{2}$, just one hour was needed to reach the concentration threshold of $0.05 \mathrm{mg} \cdot \mathrm{L}^{-1}$, as opposed to the six and a half hours required for the thiabendazole. The Fenton process saw this time reduced to just 30 minutes, with additionally the need for illumination obviated.

With respect to mineralization, as for thiabendazole, the TOC showed a much more favourable evolution when a $\mathrm{TiO}_{2}$ based catalyst was applied in combination with activated carbon than with the application of any other of the tested processes. However, the beneficial effect of the activated carbon in terms of mineralization kinetics was not so marked as for the case of thiabendazole. For its part, the Fenton process displayed very slow mineralization.

With respect to toxicity, though there was clear final detoxification of the sample with all the processes, the photocatalytic processes stand out against the Fenton process. This was probably due to traces of $\mathrm{H}_{2} \mathrm{O}_{2}$ present in the sample, as catalase was not used in the tests conducted with imazalil sulphate since it was not considered necessary due to the low concentrations of $\mathrm{H}_{2} \mathrm{O}_{2}$ employed.

In general, the degradation kinetics were faster than those of mineralization. However, this did not have a negative effect on detoxification of the solution, as complete detoxification of the sample was achieved by the end of all the reactions. This would seem to indicate that 
the toxicity was closely related to the fungicides under study and that their degradation compounds, at the concentrations produced, were less toxic than the initial compound, or even, at reaction times greater than 60 minutes, acted as nutrients.

In summary, the Fenton process showed itself to be the most favourable option in the treatment of this type of wastewater. In addition to short degradation times, implementation of this process is the most economic from an engineering point of view.

The concentrations of reagents used in the Fenton process are relatively low. It should be mentioned that for both thiabendazole and imazalil sulphate, the concentrations of $\mathrm{H}_{2} \mathrm{O}_{2}$ used were lower than those calculated theoretically [11], namely $0.51 \mathrm{~mL} \cdot \mathrm{L}^{-1}$ and $0.16 \mathrm{~mL} \cdot \mathrm{L}^{-1}$ for thiabendazole and imazalil sulphate, respectively. It is also known that high concentrations of peroxide can give rise to competitive reactions which produce an inhibitory effect on degradation of the substrate [14]. For this reason, the use of small quantities of this reagent is beneficial not only from an economic point of view, but also in terms of the final quality of the treated water. It has been shown that excess hydrogen peroxide generates interferences in measurements of toxicity in samples [24]. Though this particular parameter is not subject to legislation, in terms of reusing the treated water for irrigation purposes its use would not be appropriate.

Table 2 shows the results of the analysis of other chemical parameters of the wastewater after application of the Fenton process together with the legally permitted margins for water reuse for agricultural purposes. These parameters are water quality indicators [25-29] which must be fully studied and measured before treated wastewater is disposed of into the environment or reused. It can be observed in the Table that all the parameters are within the permitted margins and, therefore, this water can be reused for agricultural purposes.

\section{Conclusions}

The efficiency of advanced oxidation techniques has been demonstrated in the decontamination and detoxification of thiabendazole-based and imazalil sulphatebased water used in the postharvest treatment of bananas. However, Fenton and photo-Fenton processes displayed the greatest efficiency in the degradation of these fungicides in water.

The Fenton process requires lower amounts of reagents and is the simplest in terms of system design, making it the most economic from both an economic and maintenance point of view. Should further studies on a prototype or industrial scale system be instigated, it is particularly recommendable for wastewaters resulting from postharvest treatment of bananas.
Table 2. Parameters of the water after treatment and legally permitted levels.

\begin{tabular}{cccc}
\hline Parameters & $\begin{array}{c}\text { Fenton } \\
\text { Thiabendazole }\end{array}$ & $\begin{array}{c}\text { Fenton Imazalil } \\
\text { sulphate }\end{array}$ & $\begin{array}{c}\text { Legislation } \\
(\mathrm{RD} \\
1620 / 2007)\end{array}$ \\
\hline $\begin{array}{c}\text { Concentration } \\
\left(\mathrm{mg} \cdot \mathrm{L}^{-1}\right)\end{array}$ & $<0.05$ & $<0.05$ & 0.05 \\
$\mathrm{pH}$ & 7.5 & 7.5 & $5.5-9.5$ \\
$\mathrm{BOD} 5\left(\mathrm{mg} \cdot \mathrm{L}^{-1}\right)$ & $<20$ & $<20$ & 25 \\
$\mathrm{COD}\left(\mathrm{mg} \cdot \mathrm{L}^{-1}\right)$ & 70.29 & 72.29 & 125 \\
$\mathrm{SS}\left(\mathrm{mg} \cdot \mathrm{L}^{-1}\right)$ & 9 & 9 & 35 \\
$\begin{array}{c}\mathrm{Nitrates}\left(\mathrm{mg} \cdot \mathrm{L}^{-1}\right) \\
\mathrm{Nitrites}\left(\mathrm{mg} \cdot \mathrm{L}^{-1}\right)\end{array}$ & 0.08 & 0.02 & 10 \\
$\begin{array}{c}\mathrm{Sulphates} \\
\left(\mathrm{mg} \cdot \mathrm{L}^{-1}\right)\end{array}$ & 0 & 0 & \\
$\begin{array}{c}\mathrm{Chlorides} \\
\left(\mathrm{mg} \cdot \mathrm{L}^{-1}\right)\end{array}$ & 5.97 & 5.95 & 2000 \\
\hline
\end{tabular}

Finally, particular mention should be made of the fact that, according to the legislation in force, all the processes studied in this paper resulted in a water quality of a standard suitable for reuse in irrigation.

\section{Acknowledgements}

The authors would like to express their thanks to COPLACA for supplying the water studied in this work, which forms part of the chemical engineering end of degree project submitted in September, 2009, at Las Palmas de Gran Canaria, entitled "Decontamination process for fungicides in water used for banana washing with advanced photochemical oxidation techniques" (translation of original title in Spanish).

We wish to thank the Spanish Ministry of Science and Innovation for their financial support through the Project CTQ2008-05961-C02-02

\section{References}

[1] Coplaca, "Pudrición de Corona en el Plátano Canario," Coplaca, Canarias, 2004.

[2] Boletín Oficial de Canarias (BOC), "Decreto 174/1994, de 29 Julio, por el que se Aprueba el Reglamento de Control de Vertidos para la Protección del Dominio Público Hidráulico," Boletín Oficial de Canarias, Vol. 104, No. 230, 1994, pp. 6123-6141.

[3] Boletín Oficial de Canarias (BOC), "Decreto 82/1999, de 6 de Mayo, por el que se Aprueba el Plan Hidrológico Insular de Gran Canaria," Boletín Oficial de Canarias, Vol. 73, No. 73, 1999, pp. 8382-8436.

[4] J. A. Arroyave Rojas, L. F. Garcés Giraldo and A. F. Cruz Castellanos, "Fotodegradación del Pesticida Mertect Empleando Foto- Fenton con láMpara de luz Ultravioleta," Revista Lasa- llista de Investigación, Vol. 3, No. 2, 2006, pp. 19-24. 
[5] J. A. Arroyave Rojas, L. F. Garcés Giraldo and A. F. Cruz Castellanos, "Fotodegradación de las Aguas Residuales con Pesticida Mertect en la Industria Bananera Empleando Fotocatálisis con Dióxido de Titanio y Lámpara de luz Ultravioleta," Revista Lasallista de Investigación, Vol. 4, No. 1, 2007, pp. 1-7.

[6] J. Araña, C. G. i Cabo and C. F. Rodríguez, "Combining $\mathrm{TiO}_{2}$-Photocatalysis and Wetland Reactors for the Efficient Treatment of Pesticides," Chemosphere, Vol. 71, No. 4, 2008, pp. 788-794. doi:10.1016/j.chemosphere.2007.10.008

[7] S. Malato, J. Blanco and J. Cáceres, "Photocatalytic Treatment of Water-Soluble Pesticides by Photo-Fenton and $\mathrm{TiO}_{2}$ Using Solar Energy," Catalysis Today, Vol. 76, No. 2-4, 2002, pp. 209-220. doi:10.1016/S0920-5861(02)00220-1

[8] J. B. Gálvez, S. M. Rodríguez and C. A. E. Gasca, "Purificación de Aguas por Fotocatálisis Heterogénea: Estado del Arte," In: M. A. Blesa, Ed., Eliminación de Contaminantes por Fotocatálisis Heterogénea, La Plata, Argentina por Gráfica, 2001, pp. 51-76.

[9] J. Araña, J. M. Doña-Rodríguez and E. T. Rendón, " $\mathrm{TiO}_{2}$ Activation by Using Activated Carbon as a Support. Part II. Photoreactivity and FTIR Study," Applied Catalysis B: Environmental, Vol. 44, No. 2, 2003, pp. 153-160.

[10] J. Araña, J. M. Doña-Rodríguez and E. T. Rondón, “TiO2 Activation by Using Activated Carbon as a Support. Part I. Surface Characterisation and Decantability Study," Applied Catalysis B: Environmental, Vol. 44, No. 2, 2003, pp. 161-172.

[11] J. C. Velázquez, "Evalución Analítica y Optimización de Procesos de Oxidación Avanzada en Planta Piloto Solar," Ph.D Thesis, Almeria University, Almeria, 2002.

[12] S. H. Lin and C. C. Lo, "Fenton Process for Treatment of Desizing Wastewater," Water Research, Vol. 8, No. 31, 1997, pp. 2050-2056. doi:10.1016/S0043-1354(97)00024-9

[13] A. Safarzadeh-Amiri, J. R. Bolton and S. R. Cater, "Ferrioxalate-Mediated Solar Degradation of Organic Contaminants in Water," Solar Energy, Vol. 56, No. 5, 1996, pp. 439-443. doi:10.1016/0038-092X(96)00002-3

[14] X. Domènech, W. F. Jardim and M. I. Litter, "Procesos Avanzados de Oxidación Para la Eliminación de Contaminantes," In: M. A. Blesa, Ed., Eliminación de Contaminantes por Fotocatálisis Heterogénea, La Plata, Argentina por Gráfica, 2001, p. 24.

[15] H. D. Burrows, L. M. Canle and J. A. Santaballa, "Reaction Pathways and Mechanisms of Photodegradation of Pesticides," Photochemistry and Photobiology, Vol. 67, No. 2, 2002, pp. 71-108. doi:10.1016/S1011-1344(02)00277-4

[16] S. Chiron, A. Fernandez-Alba, A. Rodriguez and E. Garcia-Calvo, "Pesticide Chemical Oxidation: State-of-theArt," Water Research, Vol. 34, No. 2, 1999, pp. 366-377.
[17] J. L. Acero, F. J. Benitez, M. Gonzalez and R. Benitez, "Kinetics of Fenuron Decomposition by Single-Chemical Oxidants and Combined Systems," Industrial \& Engineering Chemistry Research, Vol. 41, No. 17, 2002, pp. 4225-4232.

[18] A. C. S. C. Teixeira, L. Mendes and G. Stollar, "PhotoFenton Remediation of Wastewaters Containing Agrochemicals," Brazilian Archives of Biology and Technology, Vol. 48, No. Spe., 2005, pp. 207-218. doi:10.1590/S1516-89132005000400026

[19] S. A. S. Alvear, "Evaluación de la Aplicación en Postcosecha del Fungicida 'Pyrimethanil' via Termonebulización en el Control de Botrytis Cinerea en Manzana cv. Fuji," Agricultural Science Faculty, Agronomy School, Chile, 2003.

[20] H. Kaiser, "Die Berechnung der Nachweisempfindlichkeit," Spectrochimica Acta, Vol. 3, No. 1, 1947, pp. 4067. doi:10.1016/0371-1951(47)80005-0

[21] APHA, "Standard Methods for the Examination of Water and Wastewater," Washington DC, 2005.

[22] J. Blanco Gálvez, S. Malato Rodríguez, C. A. Estrada Gasca, E. R. Bandala, S. Gelover and T. Leal. "Purificación de Aguas por Fotocatálisis Heterogénea," In: M. A. Blesa, Ed., Eliminación de Contaminantes por FotocatÁlisis Heterogénea, La Plata, 2001, pp. 51-76.

[23] J. A. H. Melián, J. Araña and J. A. Ortega, "Comparative Study of Phenolics Degradation between Biological and Photocatalytic Systems," Journal of Solar Energy Engineering, Vol. 130, No. 4, 2008, pp. 1-7.

[24] A. Bozzi, M. Dhananjeyan and I. Guasaquillo, "Evolution of Toxicity during Melamine Photocatalysis with $\mathrm{TiO}_{2}$ Suspensions," Journal of Photochemistry and Photobiology A: Chemistry, Vol. 162, No. 1, 2004, pp. 179-185.

[25] Real Decreto 140/2003, de 7 de febrero, por el que se establecen los criterios sanitarios de la calidad del agua de consumo humano, Boletín Oficial del Estado, No. 45, 2003, pp. 7228-7245.

[26] Real Decreto 261/1996, de 16 de febrero, sobre protección de las aguas contra la contaminación producida por los nitratos procedentes de fuentes agrarias, Boletín Oficial del Estado, No. 61, 1996, pp. 9734-9737.

[27] Real Decreto 1620/2007, de 7 de diciembre, por el que se establece el régimen jurídico de la reutilización de las aguas depuradas, Boletín Oficial del Estado, No. 294, 2007, pp. 50639-50661.

[28] C. G. i Cabo, "Estrategias de Optimización de Procesos de Descontaminación de Efluentes Acuosos y Gaseosos Mediante Fotocatálisis Heterogénea," Ph.D Thesis, Universidad de Las Palmas de Gran Canaria, Las Palmas de Gran Canaria, Spain, 2007.

[29] H.-C. Su and A.-Y. Lin, "High Performance Liquid Chromatographic Determination of Imazalil Residue in Agricultural Products," Journal of Food and Drug Analysis, Vol. 11, No. 4, 2003, pp. 296-301. 